\title{
A Computational Study of the Ozonolysis of Phenanthrene
}

\author{
M.H. Almatarneh*, E. Al-Shamaileh, Z.M. Ahmad, A.A.-A.A. Abu-Saleh \\ AND I.A. ELAYAN
}

The University of Jordan, Department of Chemistry, Amman, 11942, Jordan

\begin{abstract}
A computational study of the ozonolysis of phenanthrene has been carried out using DFT methods (B3LYP and M06-2X). The reaction mechanism for the ozonolysis was studied in both gas phase and in solution, using the polarizable continuum solvation model. The structures for all proposed reaction mechanisms were optimized using M06-2X and B3LYP methods with 6-31G(d), 6-31+G(d), and 6-31G(2df,p) basis sets. In solution, all structures were optimized using B3LYP/6-31+G(d,p) and polarizable continuum solvation model. Six different mechanistic pathways were explored for the ozonolysis of phenanthrene that forms aldehyde compounds. The activation energy of the formation of the primary ozonide intermediate in pathway $\mathrm{A}$ is $13 \mathrm{~kJ} \mathrm{~mol}^{-1}$ in the polarizable continuum model with the B3LYP $/ 6-31+\mathrm{G}(\mathrm{d}, \mathrm{p})$ method. This reaction is followed by a dissociation into a zwitterionic Criegee intermediate with an activation energy of $76 \mathrm{~kJ} \mathrm{~mol}^{-1}$ in polarizable continuum model with B3LYP $/ 6-31+\mathrm{G}(\mathrm{d}, \mathrm{p})$. Furthermore, the nucleophilic addition reactions of methanol to the Criegee intermediate have been studied along two pathways, B1 and B2. The water-mediated mechanism for pathways B2 and C2, where the water molecule acts as a mediator through a 1,5-proton shift, dropped the activation barriers by 18 and $26 \mathrm{~kJ} \mathrm{~mol}^{-1}$, respectively, based on B3LYP/6-31G(2df,p) method. The solvation model (polarizable continuum) reduces the energy barriers for all pathways except for the reaction of methanol with the Criegee intermediate. This study provides an insight into understanding the mechanism of transformation of this pollutant into non-toxic compounds.
\end{abstract}

DOI: 10.12693/APhysPolA.132.1149

PACS/topics: Ozonolysis of Phenanthrene, Primary Ozonide, Criegee Intermediate

\section{Introduction}

Polycyclic aromatic hydrocarbons (PAHs) are organic compounds which contain multiple aromatic rings. These compounds are characterized as nonpolar, lipophilic, and insoluble in water. They are present in air, soil, and sediments as by-products of incomplete natural combustion of organic materials [1]. In general, PAHs create a great concern since they exhibit mutagenic and carcinogenic character, and are therefore hazardous to human health [2].

Phenanthrene (tricyclo[8.4.0.0]tetradeca-1,3,5,7,9,11,13-heptaene) is one of the PAHs compounds with the chemical formula of $\mathrm{C}_{14} \mathrm{H}_{10}$, consisting of three fused benzene rings $[1,3]$. It is one of the three main constituents of the anthracene oil fraction of coal tar distillation. It is usually used in the manufacture of dyes and in the synthesis of some pharmaceutical products [4]. Some derivatives of phenanthrene [5] have antimalarial [6], antioxidant [7], and antimicrobial activity [8,9]. On the other hand, phenanthrene is present in cigarette smoke [3] and is very toxic, since upon inhalation it leads to genetic mutations that may cause cancer, and particularly the lung cancer [10].

The interaction of ozone (ozonolysis) with alkenes was proposed by Rudolf Criegee in 1953. The ozonolysis reaction is the oxidation of alkenes or alkynes with ozone to form low vapor pressure organic compounds, in which the multiple $\mathrm{C}=\mathrm{C}$ bond is converted to a primary ozonide

*corresponding author; e-mail: m.almatarneh@ju.edu.jo
(POZ). The POZ eventually dissociates into a carbonyl oxide (Criegee intermediate) and an aldehyde or ketone [11]. The Criegee intermediate (CI) is a highly reactive carbonyl oxide that is collisionally stabilized, hence, it undergoes unimolecular or bimolecular reactions. The unimolecular dissociation occurs through either of the vinyl hydroperoxide or ester channels. Furthermore, the CI may undergo bimolecular reactions with species present in the atmosphere, such as $\mathrm{H}_{2} \mathrm{O}$ and its clusters [12], $\mathrm{CO}_{x}$ [13], $\mathrm{NH}_{3}$ [14]. Recently, Su et al. [15] measured the infrared spectrum of the simplest Criegee intermediate $\left(\mathrm{H}_{2} \mathrm{COO}\right)$ in the gas phase. Their spectral results have confirmed that the $\mathrm{CI}$ is a zwitterion intermediate (Fig. 1), rather than a biradical one.

Jrrgensen and Gross [14] studied the reaction between different CI's of $\mathrm{H}_{2} \mathrm{COO}, \mathrm{CH}_{3} \mathrm{HCOO}$, and $\left(\mathrm{CH}_{3}\right)_{2} \mathrm{COO}$ with $\mathrm{NH}_{3}$ through the formation of hydroperoxide alkylamines. They have reported the rate constants, calculated using the G3 approach, of $1.8 \times 10^{-13}, 6.9 \times 10^{-14}$ and $5.1 \times 10^{-18} \mathrm{~cm}^{-1}$ per molecule per second, for $\mathrm{H}_{2} \mathrm{COO}$, $\mathrm{CH}_{3} \mathrm{HCOO}$, and $\left(\mathrm{CH}_{3}\right)_{2} \mathrm{COO}$, respectively.

Furthermore, the reactions of the CI of $\beta$-pinene with $\mathrm{H}_{2} \mathrm{O}$ and its dimer, through the formation of $\alpha$ hydroxy hydroperoxide have shown that the dimer reactions are faster with lower activation energies, less than $36 \mathrm{~kJ} \mathrm{~mol}^{-1}$, using M06-2X/6-311+G(2d,p) method [12]. The reactions of the $\mathrm{CI}$ of limonene with $\mathrm{H}_{2} \mathrm{O}$ have been reported, with the most plausible pathway having an activation energy of $62 \mathrm{~kJ} \mathrm{~mol}^{-1}$ [16]. In addition, Vereecken et al. [17] studied the reaction of CI with NO. They found that the activation energy for the most favorable pathway is $24 \mathrm{~kJ} \mathrm{~mol}^{-1}$, using $\operatorname{CCSD}(\mathrm{T}) / \mathrm{M} 05-$ 2X/aug-cc-pVDZ method. 
Recent theoretical studies have been performed for the reaction of ozone with the simplest $\mathrm{CI}\left(\mathrm{H}_{2} \mathrm{COO}\right)$. The reaction leads to the formation of formaldehyde and two $\mathrm{O}_{2}$ molecules [18, 19]. The ozonolysis of limonene has been found to have a total rate of $2.92 \times 10^{-16} \mathrm{~cm}^{3}$ molecule ${ }^{-1} \mathrm{~s}^{-1}$, using $\operatorname{CCSD}(\mathrm{T})+\mathrm{CF}$ method [20]. The ozonolysis of $\alpha$-pinene and $\beta$-pinene through the POZ formation occurs with an activation barrier of 1.3 and $8 \mathrm{~kJ} \mathrm{~mol}^{-1}$, using the $\operatorname{CCSD}(\mathrm{T})+\mathrm{CF}[21]$. The barriers of the ozonolysis of $\beta$-pinene for different orientations are 10 and $8 \mathrm{~kJ} \mathrm{~mol}^{-1}$, using the CBS-QB3 [22]. Thereafter, the cleavage of POZ yields carbonyl oxides, with barrier heights in the range of 51 to $73 \mathrm{~kJ} \mathrm{~mol}^{-1}$, based on $\operatorname{CCSD}(\mathrm{T})+\mathrm{CF}[21]$.

The ozonolysis of phenanthrene occurs at $\mathrm{C} 9=\mathrm{C} 10$ bond, that lies between the two benzene rings, leading to the formation of 2,2'-biphenyldialdehyde [23]. In 1956, Bailey has studied the ozonolysis of phenanthrene in methanol. His results support the Criegee mechanism for the ozonolysis, where the decomposition of the active oxygen containing compounds leads to the formation of a 2,2 'biphenyldicarboxaldehyde, methyl 2'-formyl-2-biphenylcarboxylate, 2'-formyl-2-biphenylcarboxylic acid, and diphenic acid [24]. In the same year, Ringold and Rosenhranz studied the ozonolysis of phenanthrene in chloroform, and the products appeared to be a mixture of the polymer and an acetoxy hydroperoxide [25]. Furthermore, additional results of ozonolyses, both in reactive and in inert solvents, were reported [26].

Rigby et al. studied Diels-Alder dimerization of cyclopenta[1]phenanthrene using isodibenzindene [27]. This study has reported results of the X-ray crystallographic, computational, and NMR spectroscopic investigations. The geometry optimization has been confirmed using HF/3-21G(d)method [27]. Furthermore, Huh reported a successful method for the ozonolysis of phenanthrene adsorbed on powdered polyethylene, that can be applied for a large-scale preparation of ozonides [28]. Bae et al. [29] explored the impact of the genetic material 1,4-difluorobenzo[c]phenanthrene $(1,4-\mathrm{DFBcPh})$ on the DNA and its distortions. This study has covered the crystallographic, computational, and biological investigations of the compound. The results have shown that the presence of fluorine atoms gives unusual quasi-diaxial hydroxyl group.

To the best of our knowledge, no computational study was reported for the mechanism of the ozonolysis of phenanthrene, which would explain how this reaction takes place. Therefore, a detailed computational study of the ozonolysis of phenanthrene has been performed using high-level ab initio and DFT calculations. It is hoped that this computational study would benefit experimentalists, by providing more detailed information about this reaction, and possibly aid in the design of new experiments for further understanding and development of synthetic procedures for the reaction products.

Scheme 1, shows the proposed mechanism for the ozonolysis of phenanthrene. Ozone (2) reacts according to a 1,3-dipolar addition reaction with phenanthrene (1).
The resulting POZ (3), decays into the zwitterion compound (4), which is attacked by hydroxide ion $\mathrm{OH}^{-}$, giving the hydroxyl peroxide hemiacetal (5). Finally, the ozonolysis of the peroxide $(5)$ is reduced in an acidic medium, yielding the final product dialdehyde (6).

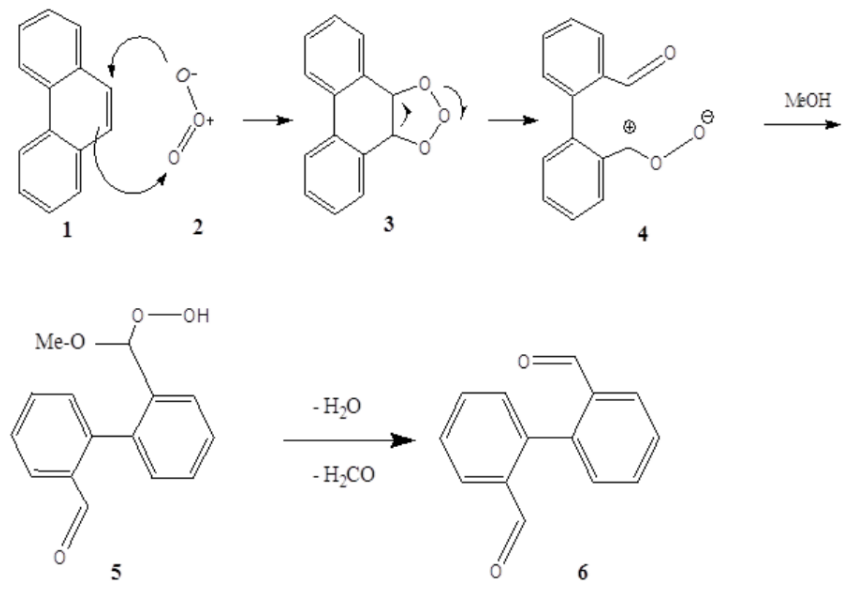

Scheme 1: Proposed mechanism of the ozonolysis reaction of phenanthrene.

\section{Computational method}

The ozonolysis of phenanthrene has been studied using DFT calculations. All calculations were performed using Gaussian 09 quantum chemistry (G09) package [30]. This work involves non-covalently bonded complexes, and the M06-2X method is suitable for non-covalent interactions. The DFT calculations were done using the B3LYP [31, 32] and M06-2X [33]. Rezac and Hobza reported for the non-covalently bonded systems that the basis set, used in the combination with M06, is highly recommended to include diffusion functions [34, 35]. Different basis sets have been used to investigate the effect of polarization and diffuse functions, such as: $6-31 \mathrm{G}(\mathrm{d})$, $6-31 \mathrm{G}(2 \mathrm{df}, \mathrm{p}), 6-31+\mathrm{G}(\mathrm{d}, \mathrm{p})$, and $6-311 \mathrm{G}++(3 \mathrm{df}, 3 \mathrm{pd})$. It has also been shown that dispersion and long-range corrected DFT methods (such as M06) perform significantly better in hydrogen-bonded systems, when compared to B3LYP. Therefore, M06-2X was used to increase the reliability of both the geometries and the energies.

The optimized geometries of the reactants, transition states, intermediates, and products were determined both in the gas and aqueous phases, using the PCM model [36]. Intrinsic reaction coordinate (IRC) calculations [37-39] were used to characterize the transition states (TS) on the potential energy surface (PES). To ensure the presence of only one imaginary frequency in the transition states, frequency analyses were performed. The minima were also confirmed by making sure of the absence of any imaginary frequencies. Furthermore, the thermodynamic functions $\Delta H$ and $\Delta G$, activation energies $E_{a}$ and the Gibbs energies of activation $\Delta G^{\#}$ were also calculated for each reaction pathway under investigation. The energies of all optimized structures are corrected with zero-point vibrational energies. 


\section{Results and discussion}

\subsection{The structure of phenanthrene}

The structure of phenanthrene has been optimized using the B3LYP/6-311++G(3df,3pd) method. Figure 1 depicts the optimized ground state geometry of phenanthrene. The selected structural parameters for phenanthrene structure, optimized using B3LYP/6$311++\mathrm{G}(3 \mathrm{df}, 3 \mathrm{pd})$ method, are listed in Table I.

This study shows that a ground-state single phenanthrene molecule has a planar structure, where the dihedral angles of $\mathrm{C}_{11}-\mathrm{C}_{10}-\mathrm{C}_{9}-\mathrm{C}_{14}, \mathrm{C}_{11}-\mathrm{C}_{12}-\mathrm{C}_{13}-\mathrm{C}_{14}$, and $\mathrm{C}_{4}-\mathrm{C}_{12}-\mathrm{C}_{13}-\mathrm{C}_{5}$ are equal to $0.000^{\circ}$. Furthermore, the point group of phenanthrene molecule is $C_{2} v$. These data are in excellent agreement with the experimental $\mathrm{X}$-ray data [40], see Table I, differing by no more than $0.020 \AA$, except for the $\mathrm{C}_{10}-\mathrm{C}_{11}$ and $\mathrm{C}_{1}-\mathrm{C}_{11}$ bond lengths (0.041 and $0.047 \AA$, respectively).
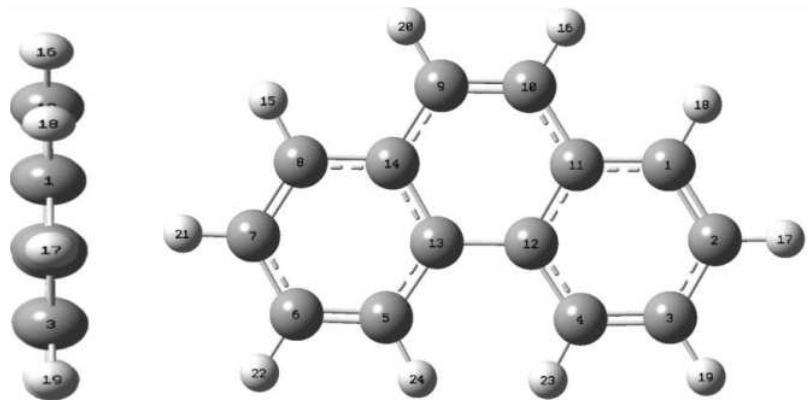

Fig. 1. The optimized geometry of phenanthrene (side and front views), obtained using B3LYP/6$311++\mathrm{G}(3 \mathrm{df}, 3 \mathrm{pd})$.

Furthermore, the $\mathrm{C}-\mathrm{H}$ bond lengths are in agreement with the experimental neutron diffraction analysis data [41], differing by no more than $0.020 \AA$. While for the $\mathrm{C}_{1}-\mathrm{H}_{18}$ and $\mathrm{C}_{10}-\mathrm{H}_{16}$ bond lengths, they differ by 0.083 and $0.107 \AA$, respectively. It can be noted that the $\mathrm{C}_{9}-\mathrm{C}_{10}$ bond has the shortest length in the molecule, with the calculated and measured values of 1.354 and $1.372 \AA$, respectively. On the other hand, the $\mathrm{C}_{12}$ $\mathrm{C}_{13}$ bond has the longest length in the molecule, with the calculated and measured values of 1.453 and $1.448 \AA$, respectively. This may be attributed to five non-excited resonance structures of phenanthrene.

\subsection{Potential energy surface of the ozonolysis reaction of phenanthrene (pathway A)}

This pathway involves a two-step mechanism, designated as pathway A. The first step involves a 1,3-dipolar cycloaddition of the ozone to phenanthrene. This leads to the formation of a primary ozonide (POZ). The second step is a concerted cleavage of the POZ into a Criegee intermediate and an aldehyde. The optimized structures of reactant, transition states, intermediates, and product for pathway A, are shown in Fig. 2. The potential energy surface for different calculation methods is shown
TABLE I

Selected bond lengths $(\AA)$ corresponding to the optimized geometry of phenanthrene (Fig. 1).

\begin{tabular}{c|c|c}
\hline \hline \multirow{2}{*}{ Bond } & \multicolumn{2}{|c}{ Bond lengths $[\AA]$} \\
\cline { 2 - 3 } & B3LYP $/ 6-311++\mathrm{G}(3 \mathrm{df}, 3 \mathrm{pd})$ & Experimental \\
\hline $\mathrm{C}_{1}-\mathrm{C}_{2}$ & 1.374 & $1.381^{a}$ \\
$\mathrm{C}_{2}-\mathrm{C}_{3}$ & 1.403 & $1.398^{a}$ \\
$\mathrm{C}_{3}-\mathrm{C}_{4}$ & 1.377 & $1.383^{a}$ \\
$\mathrm{C}_{9}-\mathrm{C}_{10}$ & 1.354 & $1.372^{a}$ \\
$\mathrm{C}_{10}-\mathrm{C}_{11}$ & 1.431 & $1.390^{a}$ \\
$\mathrm{C}_{11}-\mathrm{C}_{12}$ & 1.421 & $1.404^{a}$ \\
$\mathrm{C}_{12}-\mathrm{C}_{13}$ & 1.453 & $1.448^{a}$ \\
$\mathrm{C}_{1}-\mathrm{C}_{11}$ & 1.410 & $1.457^{a}$ \\
$\mathrm{C}_{4}-\mathrm{C}_{12}$ & 1.410 & $1.405^{a}$ \\
$\mathrm{C}_{1}-\mathrm{H}_{18}$ & 1.083 & $1.00^{b}$ \\
$\mathrm{C}_{2}-\mathrm{H}_{17}$ & 1.082 & $1.08^{b}$ \\
$\mathrm{C}_{3}-\mathrm{H}_{19}$ & 1.082 & $1.09^{b}$ \\
$\mathrm{C}_{4}-\mathrm{H}_{23}$ & 1.080 & $1.08^{b}$ \\
$\mathrm{C}_{9}-\mathrm{H}_{20}$ & 1.083 & $1.06^{b}$ \\
$\mathrm{C}_{10}-\mathrm{H}_{16}$ & 1.083 & $1.19^{b}$ \\
\hline
\end{tabular}

${ }^{a}$ Experimental data taken from [40].

${ }^{b}$ Experimental data taken from [41].
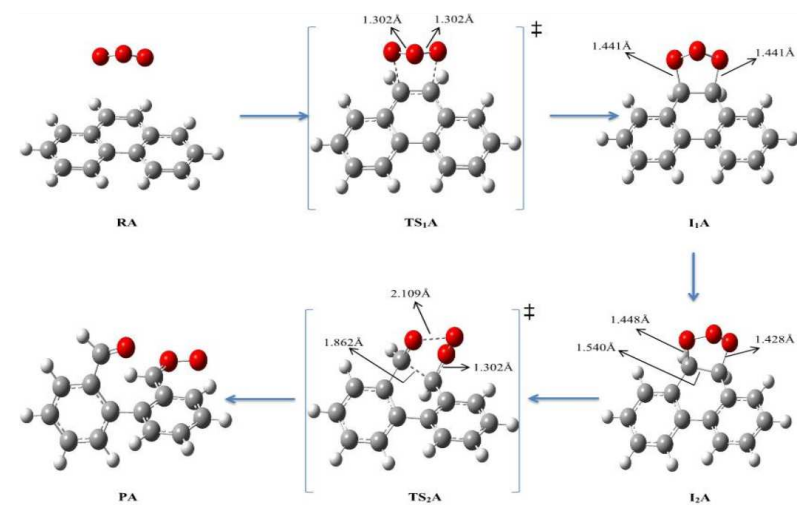

Fig. 2. Optimized geometries of the ozonolysis of phenanthrene for B3LYP/6-31G(2df,p) (pathway A).

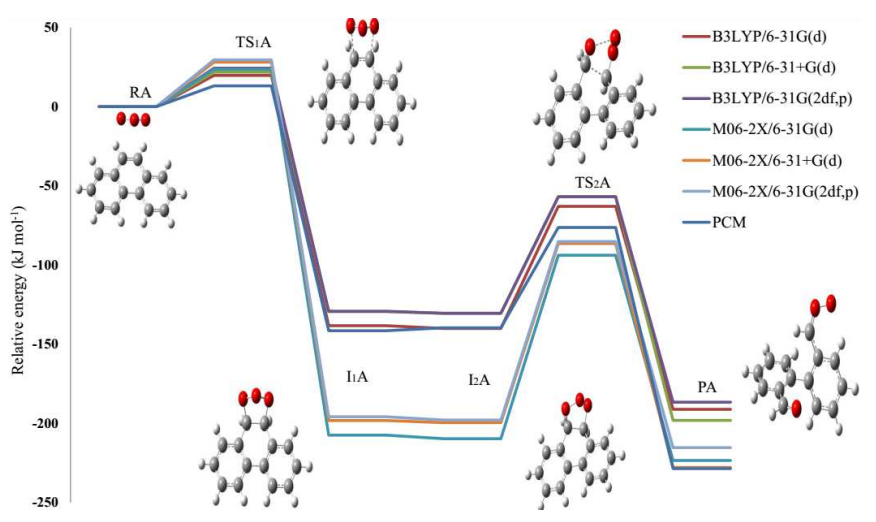

Fig. 3. PES for the ozonolysis of phenanthrene (pathway A) relative energies, calculated using different methods (in $\mathrm{kJ} \mathrm{mol}^{-1}$ ). 
TABLE II

Activation energies and Gibbs energies of activation for the ozonolysis of phenanthrene ( $\mathrm{kJ} \mathrm{mol}^{-1}$, pathway A).

\begin{tabular}{c|c|c|c|c}
\hline \hline \multirow{2}{*}{ Theory/basis set } & \multicolumn{2}{|c|}{$\mathrm{TS}_{1} \mathrm{~A}$} & \multicolumn{2}{c}{$\mathrm{TS}_{2} \mathrm{~A}$} \\
\cline { 2 - 5 } & $E_{a}$ & $\Delta G^{\#}$ & $E_{a}$ & $\Delta G^{\#}$ \\
\hline B3LYP/6-31G(d) & 15 & 33 & 77 & 80 \\
B3LYP/6-31G(2df,p) & 20 & 38 & 74 & 76 \\
B3LYP/6-31+G(d) & 17 & 41 & 74 & 76 \\
M06-2X/631G(d) & 20 & 32 & 116 & 118 \\
M06-2X/6-31G(2df,p) & 26 & 38 & 113 & 115 \\
M06-2X/631+G(d) & 24 & 41 & 113 & 115 \\
PCM $^{a}$ & 13 & 13 & 63 & 66 \\
\hline$a$ Calculations have been done using B3LYP/6- \\
31+G(d,p)method.
\end{tabular}

in Fig. 3. Activation energies and Gibbs energies of activation are given in Table II.

The formation of the POZ intermediate $\left(\mathrm{I}_{1} \mathrm{~A}\right)$ occurs through the transition state $\left(\mathrm{TS}_{1} \mathrm{~A}\right)$ that involves the concerted ozone addition to phenanthrene, as illustrated in Fig. 3. The bond length between the ozone molecule and $\mathrm{C}_{9}=\mathrm{C}_{10}$ bond of phenanthrene, for the reacting complex RA is $2.900 \AA$, using B3LYP/6-31G(2df,p) method. However, the bond length of ozone molecule and $\mathrm{C}_{9}=\mathrm{C}_{10}$ bond of phenanthrene in $\mathrm{TS}_{1} \mathrm{~A}$ is $2.122 \AA$. The bond length in the formed POZ $\left(\mathrm{I}_{1} \mathrm{~A}\right)$ is shortened by $0.681 \AA$ to become $1.441 \AA$. This is consistent with the bond length ranges of $1.400 \AA$ in the literature [20-22].

The first intermediate is followed by a conformational change to form $\mathrm{I}_{2} \mathrm{~A}$, where the bond lengths differ by no more than $0.027 \AA$. An elongation of the left side of the POZ, by $0.007 \AA$, is observed with an interesting change in the orientation of the center oxygen of $\mathrm{I}_{2} \mathrm{~A}$. In the second step, the POZ undergoes a concerted cleavage (dissociation), that leads to the formation of a stable aldehyde and a CI (PA) through transition state $\mathrm{TS}_{2} \mathrm{~A}$. The bond length of $\mathrm{C}_{9}-\mathrm{C}_{10}$ in $\mathrm{I}_{2} \mathrm{~A}$ is elongated from 1.540 to $1.862 \AA$, as shown in Fig. 3. The difference in the bond length of $0.322 \AA$ is consistent with the bond lengths of the POZ dissociation of $\alpha$-pinene, $\beta$-pinene [21], using B3LYP/6-31G(d,p), and sabinene [42], using B3LYP/6-31G(d) method. Furthermore, the bond length of $\mathrm{O}-\mathrm{O}$ bond cleavage in $\mathrm{TS}_{2} \mathrm{~A}$ is $2.109 \AA$, using B3LYP/6-31G(2df,p) method. In general, the bond lengths are in good agreement with the ozonolysis of monoterpenes [43-45].

The activation energies of the $\mathrm{TS}_{1} \mathrm{~A}$ and $\mathrm{TS}_{2} \mathrm{~A}$ using the B3LYP/6-31G(d), B3LYP/6-31G(2df,p), and B3LYP $/ 6-31+\mathrm{G}(\mathrm{d})$ methods are 15,20 , and $17 \mathrm{~kJ} \mathrm{~mol}^{-1}$ for $\mathrm{TS}_{1} \mathrm{~A}$, and 77,74 , and $74 \mathrm{~kJ} \mathrm{~mol}^{-1}$ for $\mathrm{TS}_{2} \mathrm{~A}$, respectively. The activation energies of $\mathrm{TS}_{1} \mathrm{~A}$ are in good agreement with the limonene (using the $\operatorname{CCSD}(\mathrm{T})+\mathrm{CF}$ ), camphene, $\alpha$-pinene, and $\beta$-pinene (using B3LYP/6$31+\mathrm{G}(2 \mathrm{~d}, 2 \mathrm{p})$ method), where the values are 12,15 , 28 and $18 \mathrm{~kJ} \mathrm{~mol}^{-1}$, respectively. Furthermore, the activation energies of $\mathrm{TS}_{2} \mathrm{~A}$ are in agreement with the $\alpha$-pinene and $\beta$-pinene values of 72 and $63 \mathrm{~kJ} \mathrm{~mol}^{-1}$, using B3LYP $/ 6-31 \mathrm{G}(\mathrm{d}, \mathrm{p})$ method [21]. However, lower energy values of 56 and $51 \mathrm{~kJ} \mathrm{~mol}^{-1}$ are observed for the $\beta$-pinene and sabinene, calculated using the CBSQB3 [22] and B3LYP/6-31G(d) [42], respectively.

The M06-2X method shows higher activation energy for both TS's, than the B3LYP functional, see Table II. However, using the PCM solvation model, there is a little change in the activation energy for the first step. The activation energy using the PCM model with B3LYP/6$31+\mathrm{G}(\mathrm{d}, \mathrm{p})$ method is $13 \mathrm{~kJ} \mathrm{~mol}^{-1}$. Employment of solvent PCM model for the second step has reduced the activation energy to $63 \mathrm{~kJ} \mathrm{~mol}^{-1}$. The barriers, obtained using PCM, drop significantly, compared to the M06-2X functional, as shown in Table II. It can be noted here, that the addition of diffuse or polarization function does not affect the energy barrier of the $\mathrm{TS}_{1} \mathrm{~A}$. Moreover, the activation energy of the phenanthrene ozonolysis, determined using the B3LYP $/ 6-31 \mathrm{G}(\mathrm{d})$ method, is comparable with those reported previously for the ozonolysis reaction of ethene [46], isoprene [47, 48], and butadiene [49].

\subsection{Potential energy surface for the reaction of} methanol with Criegee compound (pathways B1 and B2)

Two pathways are studied for the reaction of methanol with the Criegee intermediate. Pathway B1 is the non-water mediated pathway; while pathway $\mathrm{B} 2$ is the water-mediated one. For pathway B2, the water molecule acts as a mediator and participates in the proton transfer process. Methanol is one of the most abundant alcohols, present in the troposphere. It is usually found with concentrations ranging from 1 to $40 \mathrm{ppb}$ by volume [50-52].

In this study, the bimolecular reaction of methanol with the CI, denoted as pathway B1, has been studied. Figure 4 illustrates the equilibrium geometries of the reactants, transition states, and products that are included on the PES diagram for pathways B1 and B2, for different calculation methods. The activation energies and Gibbs energies of activation for the reaction are listed in Table III.

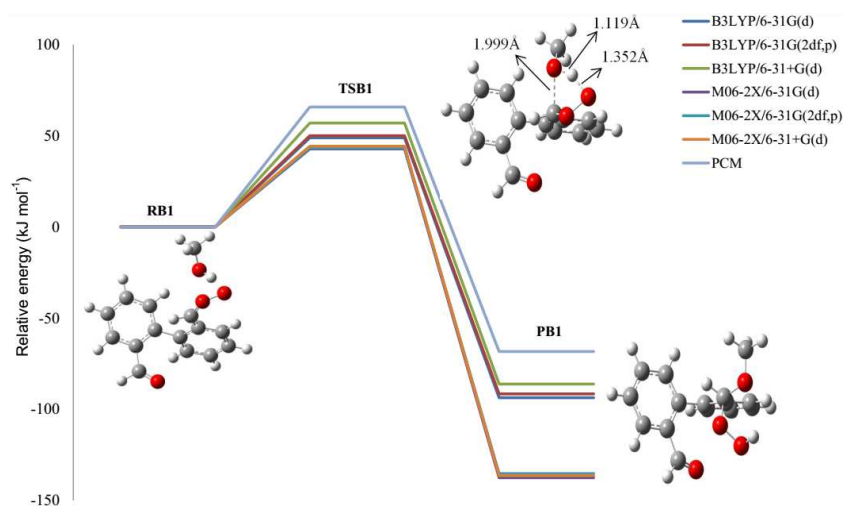

Fig. 4. PES for the reaction of methanol with Criegee compound (pathway B1). Relative energies at different levels of theory in $\mathrm{kJ} \mathrm{mol}^{-1}$. 
TABLE III

Activation energies and Gibbs energies of activation for the reaction of methanol with Criegee compound $\left(\mathrm{kJ} \mathrm{mol}{ }^{-1}\right.$, pathways B1 and B2).

\begin{tabular}{c|c|c|c|c}
\hline \hline & \multicolumn{2}{|c|}{ TS1B1 } & \multicolumn{2}{c}{ TS1B2 } \\
\hline Theory/basis set & $E_{a}$ & $\Delta G^{\#}$ & $E_{a}$ & $\Delta G^{\#}$ \\
\hline B3LYP/6-31G(d) & 49 & 58 & 31 & 46 \\
B3LYP/6-31G(2df,p) & 50 & 59 & 32 & 46 \\
B3LYP/6-31+G(d) & 57 & 68 & 45 & 61 \\
M06-2X/631G(d) & 43 & 51 & 16 & 25 \\
M06-2X/6-31G(2df,p) & 43 & 49 & 17 & 24 \\
M06-2X/631+G(d) $^{4} 44$ & 59 & 25 & 35 \\
PCM $^{a}$ & 66 & 83 & 41 & 73 \\
\hline$a$ Calculations have been done using B3LYP/6- \\
31+G(d,p) method.
\end{tabular}

The CI formed from the cleavage of the POZ (PA) will undergo a nucleophilic addition of the methanol from the oxygen moiety in the hydroxyl group to the carbonyl group of the CI, through TSB1. Simultaneously, the proton migrates from the methanol molecule to the terminal oxygen of the CI, forming the $\alpha$-methoxy hydroperoxide (PB1).

The bond length between the hydrogen and oxygen of the $\mathrm{OH}$ in methanol of the reacting species (RB1) is $1.819 \AA$, using the B3LYP/6-31G(2df,p) method. In TSB1, the bond is shortened by $0.700 \AA$ to become $1.119 \AA$. Furthermore, the hydrogen bond in the methanol, to the terminal oxygen of the CI, is $1.352 \AA$, as shown in Fig. 4. The oxygen moiety in the methanol molecule approaches the carbonyl group of the CI by $1.999 \AA$. This step leads to the stabilization of the positive charge on the CI. Moreover, the dihedral angles between the benzene rings for the geometries of RB1, TSB1, and PB1 are $56.9^{\circ}, 96.1^{\circ}$, and $98.0^{\circ}$, respectively. These changes in the dihedral angle may be due to the steric factor that results from the nucleophilic addition of methanol.

In pathway $\mathrm{B} 2$, the addition of methanol to the CI has been performed via the use of one water molecule, acting as a mediator, rather than a spectator. The previous works of the 1,3-proton shift has shown that the barrier could drop significantly when the water molecule is involved, acting as a mediator [53-65]. Figure 5 shows the one-step nucleophilic addition mechanism for the monohydrated reaction between the methanol and CI. This figure shows that the water molecule catalyzes the nucleophilic addition by forming a nearly seven-membered ring transition state, TSB2. Thereafter, the water molecule grabs the hydrogen from the hydroxyl group of methanol, and simultaneously transfers it to the terminal oxygen of the CI. The methanol moiety attacks the carbonyl of the $\mathrm{CI}$, and hence, this mechanism is a concerted one.

The activation energies of pathway $\mathrm{B} 1$ for the B3LYP/6-31G(d), B3LYP/6-31G(2df,p), and B3LYP/6$31+\mathrm{G}(\mathrm{d})$ methods are 49,50 , and $57 \mathrm{~kJ} \mathrm{~mol}^{-1}$, respectively, as listed in Table III. The activation energy for

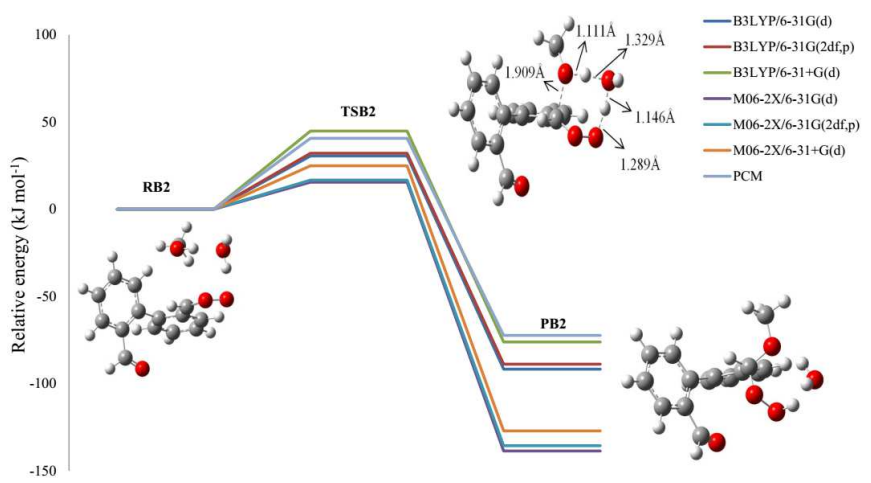

Fig. 5. PES for the reaction of methanol with Criegee compound (water-mediated mechanism) (pathway B2). Relative energies for different calculation methods are given in $\mathrm{kJ} \mathrm{mol}^{-1}$.

pathway B2 (water-mediated mechanism) is lower than that for pathway B1 (non-water-mediated mechanism). Addition of one water molecule significantly relaxes the transition state TSB2, reducing the angle strain and consequently reducing the barrier height of TSB2. The gas phase activation barriers, associated with TSB2 are 31 and $32 \mathrm{~kJ} \mathrm{~mol}^{-1}$, lower than the activation energies of TSB1, of 49 and $50 \mathrm{~kJ} \mathrm{~mol}^{-1}$, using the B3LYP/6-31G(d) and B3LYP/6-31G(2df,p) methods, respectively. The activation energy calculated using the M06-2X functional is lower than that of the B3LYP functional. The energy barriers associated with TSB2 are 16 and $17 \mathrm{~kJ} \mathrm{~mol}^{-1}$ for the M06-2X/6-31G(d) and M06-2X/6-31G(2df,p) methods, respectively. Addition of the diffuse function to the calculations increases the activation energies to both of the B3LYP $/ 6-31+\mathrm{G}(\mathrm{d})$ and M06-2X/6-31+G(d) methods, with the respective values of 45 and $25 \mathrm{~kJ} \mathrm{~mol}^{-1}$.

In comparison, the activation energy of the reaction of acetone Criegee intermediate $\left(\mathrm{CH}_{3}\right)_{2} \mathrm{COO}$ with ammonia was found to be $50 \mathrm{~kJ} \mathrm{~mol}^{-1}$, using B3LYP/6$311++\mathrm{G}(2 \mathrm{~d}, 2 \mathrm{p})$ method [14]. In another study, Jiang et al. [16] investigated the reaction of CI's from the ozonolysis of limonene with water. They found that the formation of $\alpha$-hydroxy hydroperoxide for the reaction of SCI and $\mathrm{H}_{2} \mathrm{O}$ with the activation energy of $62 \mathrm{~kJ} \mathrm{~mol}^{-1}$, is identified as the most favorable pathway using the CCSD $(\mathrm{T})+\mathrm{CF}$ (CF: correction factor) method. It should be noted here that the energy of the B3LYP/6-31G(d) method are comparable with high levels of theory used in that paper.

The activation barrier increases significantly in comparison to values of both, the B3LYP and M06-2X methods, used in this study, with activation energies of 66 and $41 \mathrm{~kJ} \mathrm{~mol}^{-1}$, if PCM model with B3LYP/6-31+G(d,p) is used for pathways B1 and B2, respectively. Based on these data, pathway B2 is more plausible for this step, as it has a lower activation energy, compared to pathway B1.

\subsection{Potential energy surface for the reactions of} $\alpha$-methoxy hydroperoxide (pathways C1 and C2)

$\alpha$-methoxy hydroperoxide (PB1), formed by the addition of methanol to the CI, will undergo a unimole- 
cular decomposition to yield an aldehyde and $\mathrm{H}_{2} \mathrm{O}$. Similarly, the role of adding one water molecule has been studied. Therefore, two pathways were considered for this reaction, denoted as pathways $\mathrm{C} 1$ and $\mathrm{C} 2$. We have found that the activation energies for pathway $\mathrm{C} 2$ (the water-mediated mechanism) were lower than that for pathway $\mathrm{C} 1$, for different calculation methods. Thus, in this section, only pathway $\mathrm{C} 2$ will be discussed and presented.

The optimized structures of reactant, transition state, and product for pathway $\mathrm{C} 2$ are included on the PES for different methods, as shown in Fig. 6. Activation energies and Gibbs energies of activation are given in Table IV for pathway $\mathrm{C} 2$. The torsion angle between the two benzene rings in the reactant $\mathrm{RC} 2$ is $102^{\circ}$, as shown in Fig. 6 .

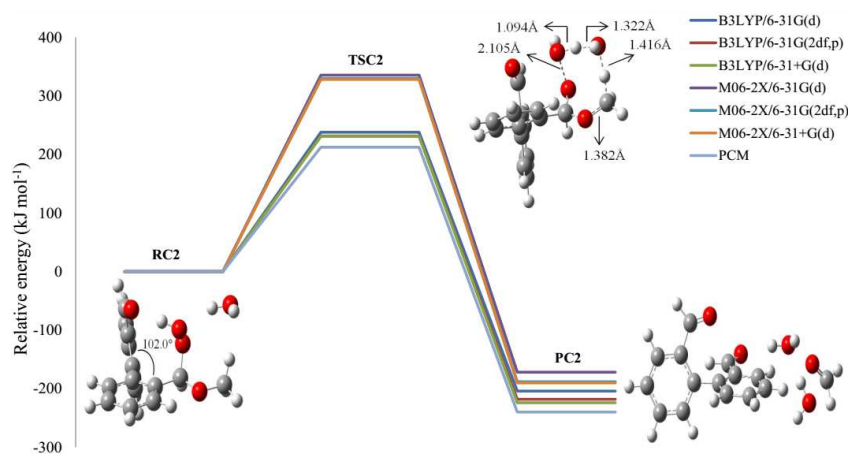

Fig. 6. PES for the unimolecular decomposition of the $\alpha$-methoxy hydroperoxide (water-mediated mechanism, pathway C2). Relative energies are given for different calculation methods, in $\mathrm{kJ} \mathrm{mol}^{-1}$.

\section{TABLE IV}

Activation energies and Gibbs energies of activation for the unimolecular reaction of hydroperoxide (watermediated mechanism) $\left(\mathrm{kJ} \mathrm{mol}^{-1}\right.$, pathways $\mathrm{C} 1$ and $\left.\mathrm{C} 2\right)$.

\begin{tabular}{c|c|c|c|c}
\hline \hline & \multicolumn{2}{|c|}{ TS1C1 } & \multicolumn{2}{c}{ TS1C2 } \\
\hline Theory/basis set & $E_{a}$ & $\Delta G^{\#}$ & $E_{a}$ & $\Delta G^{\#}$ \\
\hline B3LYP/6-31G(d) & 262 & 264 & 238 & 245 \\
B3LYP/6-31G(2df,p) & 257 & 259 & 231 & 238 \\
B3LYP/6-31+G(d) & 250 & 250 & 231 & 237 \\
M06-2X/631G(d) & 342 & 345 & 335 & 349 \\
M06-2X/6-31G(2df,p) & 338 & 341 & 329 & 343 \\
M06-2X/631+G(d) $^{3} / 332$ & 335 & 328 & 341 \\
PCM $^{a}$ & 231 & 228 & 212 & 223 \\
\hline$a$ Calculations have been done using B3LYP/6-
\end{tabular}

$31+\mathrm{G}(\mathrm{d}, \mathrm{p})$ method.

The unimolecular decomposition of the $\alpha$-methoxy hydroperoxide occurs via the proton-migration from the $\mathrm{CH}_{3}$ group to the terminal $\mathrm{OH}$ group of the hydroperoxide, to form an aldehyde and $2 \mathrm{H}_{2} \mathrm{O}$. Pathway $\mathrm{C} 2$ exhibits a similar pattern to pathway $\mathrm{B} 2$, where the $\mathrm{H}_{2} \mathrm{O}$ molecule acts as a mediator in the proton migration. The decomposition in the water-mediated step of the protonshift occurs via an eight-membered ring transition state,
TSC2, as shown in Fig. 6. Thus, the action of the mediator in the 1,5-proton shift step drops the barrier height of the reaction.

Different basis sets, used with the B3LYP functional, have been employed to calculate the activation energy of TSC2. The energy barriers for the rate-determining step of pathway $\mathrm{C} 2$ are 238,231 , and $231 \mathrm{~kJ} \mathrm{~mol}^{-1}$, using the B3LYP/6-31G(d), B3LYP/6-31G(2df,p), and B3LYP/6$31+\mathrm{G}(\mathrm{d})$ methods, respectively. However, the activation energies for TSC2 increase significantly if the M06-2X/631G(d), M06-2X/6-31G(2df,p), and M06-2X/6-31+G(d) methods are used, with the respective values of 335,329 , and $328 \mathrm{~kJ} \mathrm{~mol}^{-1}$. The energy barrier of TSC2 is lower than the energy barrier of TSC1 by $26 \mathrm{~kJ} \mathrm{~mol}^{-1}$ for B3LYP/6-31G(2df,p) method. This drop in energy is due to the presence of the $\mathrm{H}_{2} \mathrm{O}$ mediator. For TSC2, addition of diffuse or polarization functions reduces the energy barrier. Furthermore, the use of PCM solvation model has a significant role in this step. The water phase reduces the energy barrier of the TSC2 to $212 \mathrm{~kJ} \mathrm{~mol}^{-1}$, using the PCM model with B3LYP/6-31+G(d,p) method. It is worth mentioning that this reaction is found to be an exothermic and exergonic one.

\section{Conclusions}

A computational study of the ozonolysis reaction of phenanthrene, following the decomposition of the POZ that yields a CI has been carried out for conditions of the gas-phase and solution. The bimolecular reaction of methanol with the CI, forming $\alpha$-methoxy hydroperoxide in the absence and presence of water (pathways C1 and $\mathrm{C} 2$ ), both in the vacuum and in solution has been studied. Furthermore, the unimolecular decomposition reaction of the $\alpha$-methoxy hydroperoxide was studied, where the water acts as a stabilizer (pathway C1), or as a mediator (pathway $\mathrm{C} 2$ ).

The optimized geometries of reactants, transition states, intermediates, and products were determined using DFT methods with different basis sets, in the gas-phase and solution using PCM model. The bimolecular reaction of methanol and CI using one water molecule (pathway C2) is energetically more favored, compared to pathway $\mathrm{C} 1$. This is due to fact that the water molecule acts as a catalyst (proton-mediator), and therefore, the energy barrier drops significantly. It was found that the activation energies for the water-mediated mechanism (proton shift) for pathways B2 and C2 are reduced by 18 and $26 \mathrm{~kJ} \mathrm{~mol}^{-1}$, respectively, using B3LYP /6$31 \mathrm{G}(2 \mathrm{df}, \mathrm{p})$ method.

The implicit solvation model (PCM) decreased the activation energies of all pathways, except for pathways $\mathrm{C} 1$ and $\mathrm{C} 2$. Addition of polarization and diffuse functions did not significantly contribute to the decrease in the barrier heights of all pathways, except for C1 and $\mathrm{C} 2$. The thermodynamic properties of all pathways were found to be exothermic and exergonic for all calculation methods. This indicates that the reaction is favorable in the forward direction. 


\section{Acknowledgments}

We gratefully acknowledge the Atlantic Computational Excellence Network (ACENET) and Compute Canada for computer time.

The authors are grateful to the grant from the Deanship of Academic Research at the University of Jordan.

\section{Compliance with ethical standards}

The authors declare that they have no conflict of interest.

Informed consent was not required as no human or animals were involved.

This article does not contain any studies with human participants performed by any of the authors.

\section{References}

[1] A. Mrozik, Z. Piotrowska-Seget, S. Labuzek, Polish J. Environ. Stud. 12, 15 (2003).

[2] Y. Toshikazu, P.R. Lawrence, F. Wayne, G. David, D. Fcaw, A. Pryor, Case Stud. Environ. Med. 226, 1 (2009)

[3] A.C. Boström, P. Gerde, A. Hanberg, B. Jernström, T. Kyrklund, A. Rannug, M. Tornqvist, K. Victorin, R. Westerholm, Environ. Health Perspect. 110, 451 (2016).

[4] Y. Zhang, L. Huang, C. Wang, D. Gao, Z. Zuo, Chemosphere. 93, 1168 (2013).

[5] Z. Afrasiabi, E. Sinn, S. Padhye, S. Dutta, S. Padhye, C. Newton, C.E. Anson, A.K. Powell, J. Inorg. Biochem. 95, 306 (2003).

[6] E.A. Nodiff, A.J. Saggiomo, M. Shinbo, E.H. Chen, H. Otomasu, Y. Kondo, T. Kikuchi, B.L. Verma, S. Matsuura, J. Med. Chem. 15, 775 (1972).

[7] Y.Z. Zhu, S.H. Huang, B.K. Tan, J. Sun, M. Whiteman, Y.C. Zhu, Nat. Prod. Rep. 21, 478 (2004).

[8] R. Sellappan, S. Prasad, P. Jayaseelan, R. Rajavel, Rasayan J. Chem. 3, 556 (2010).

[9] M. Saffari Jourshari, M. Mamaghani, F. Shirini, K. Tabatabaeian, M. Rassa, H. Langari, Chinese Chem. Lett. 24, 993 (2013).

[10] A.R. Johnsen, L.Y. Wick, H. Harms, Environ. Pollut. 133, 71 (2005).

[11] R. Criegee, Angew. Chemie Int. Ed. English. 14, 745 (1975).

[12] X.X. Lin, Y.R. Liu, T. Huang, K.M. Xu, Y. Zhang, S. Jiang, Y.-B. Gai, W.-J. Zhang, W. Huang, RSC Adv. 4, 28490 (2014).

[13] M. Kumar, D.H. Busch, B. Subramaniam, W.H. Thompson, J. Phys. Chem. A. 118, 1887 (2014).

[14] S. Jřrgensen, A. Gross, J. Phys. Chem. A. 113, 10284 (2009).

[15] Y.-T. Su, H.-Y. Lin, R. Putikam, H. Matsui, M.C. Lin, Y.-P. Lee, Nat. Chem. 6, 477 (2014).

[16] L. Jiang, R. Lan, Y.S. Xu, W.J. Zhang, W. Yang, Int. J. Mol. Sci. 14, 5784 (2013).
[17] L. Vereecken, H. Harder, A. Novelli, Phys. Chem. Chem. Phys. 14, 14682 (2012).

[18] W.M. Wei, R.H. Zheng, Y.L. Pan, Y.K. Wu, F. Yang, S. Hong, J. Phys. Chem. A 118, 1644 (2014).

[19] H.G. Kjaergaard, T. Kurtén, L.B. Nielsen, S. Jřrgensen, P.O. Wennberg, J. Phys. Chem. Lett. 4, 2525 (2013).

[20] L. Jiang, W. Wang, Y. Xu, Chem. Phys. 368, 108 (2010).

[21] D. Zhang, R. Zhang, J. Chem. Phys. 122, 114308 (2005).

[22] T.L. Nguyen, J. Peeters, L. Vereecken, Phys. Chem. Chem. Phys. 11, 5643 (2009).

[23] W.J. Schmitt, E. Moriconi, J. Owf, Rec. Trav. Chim. Pays-Bas 78, 183 (1955).

[24] P.S. Bailey, J. Am. Chem. Soc. 78, 3811 (1956).

[25] H.J. Ringold, G.C. Rosenhranz, Communications 21, 1335 (1956).

[26] P.S. Bailey, S.B. Mainthia, J. Org. Chem. 23, 1089 (1958).

[27] S.S. Rigby, M. Stradiotto, S. Brydges, D.L.Pole, S. Top, A.D. Bain, Notes. J. Org. Chem. 3263, 3735 (1998).

[28] S.T. Huh, Bull. Korean Chem. Soc. 21, 365 (2000).

[29] S. Bae, H. Mah, S. Chaturvedi, T.M. Jeknic, W.M. Baird, A.K. Katz, H.L. Carrell, J.P. Glusker, T. Okazaki, K.K. Laali, B. Zajc, M.K. Lakshman, J. Org. Chem. 72, 7625 (2007).

[30] M.J. Frisch, G.W. Trucks, H.B. Schlegel, G.E. Suzerain, M.A. Robb, J.R. Cheeseman Jr., J.A. Montgomery, T. Vreven, K.N. Kudin, J.C. Burant, J.M. Millam, S.S. Iyengar, J. Tomasi, V. Barone, B. Mennucci, M. Cossi, G. Scalmani, N. Rega, G.A. Petersson, H. Nakatsuji, M. Hada, M. Ehara, K. Toyota, R. Fukuda, J. Hasegawa, M. Ishida, T. Nakajima, Y. Honda, O. Kitao, H. Nakai, M. Klene, X. Li, J.E. Knox, H.P. Hratchian, J.B. Cross, V. Bakken, C. Adamo, J. Jaramillo, R. Gomperts, R.E. Stratmann, O. Yazyev, A.J. Austin, R. Cammi, C. Pomelli, J.W. Ochterski, P.Y. Ayala, K. Morokuma, G.A. Voth, P. Salvador, J.J. Dannenberg, V.G. Zakrzewski, S. Dapprich, A.D. Daniels, M.C. Strain, O. Farkas, D.K. Malick, A.D. Rabuck, K. Raghavachari, J.B. Foresman, J.V. Ortiz, Q. Cui, A.G. Baboul, S. Clifford, J. Cioslowski, B. Stefanov, G. Liu, A. Liashenko, P. Piskorz, I. Komaromi, R.L. Martin, D.J. Fox, T. Keith, M.A. AlLaham, C.Y. Peng, A. Nanayakkara, M. Challacombe, P.M.W. Gill, B. Johnson, W. Chen, M.W. Wong, C. Gonzalez, J.A. Pople, Gaussian 09, Gaussian Inc., Wallingford (CT) 2003.

[31] A.D. Becke, J. Chem. Phys. 98, 5648 (1993).

[32] C. Lee, W. Yang, R.G. Lee-Yang-Parr, Phys. Rev. B 37, 785 (1988).

[33] Y. Zhao, D.G. Truhlar, Theor. Chem. Acc. 120 , 215 (2008).

[34] J. Řezáč, P. Hobza, Chem. Rev. 116, 5038 (2016).

[35] G.A. DiLabio, E.R. Johnson, A. Otero-de-la-Roza, Phys. Chem. Chem. Phys. 15, 12821 (2013).

[36] E. Cancees, B. Mennucci, J. Tomasi, J. Chem. Phys. 107, 3032 (1997). 
[37] H.P. Hratchian, H.B. Schlegel, J. Chem. Theory Comput. 1, 61 (2005).

[38] H.P. Hratchian, H.B. Schlegel, J. Chem. Phys. 120, 9918 (2004)

[39] K. Fukui, Acc. Chem. Res. 14, 363 (1981).

[40] J. Trotter, Acta Crystallogr. 16, 605 (1963).

[41] D.W. Jones, J. Yerkess, J. Mol. Struct. 1, 17 (1971).

[42] Y. Zhao, R. Zhang, H. Wang, M. He, X. Sun, Q. Zhang, J. Mol. Struct.: THEOCHEM. 942, 32 (2009).

[43] R.C.D.M. Oliveira, G.F. Bauerfeldt, J. Phys. Chem. A 119, 2802 (2015).

[44] R.C.D.M. Oliveira, G.F. Bauerfeldt, J. Chem. Phys. 137, 134306 (2012).

[45] S.A. Epstein, N.M. Donahue, J. Phys. Chem. A 114 7509 (2010)

[46] M. Olzmann, E. Kraka, D. Cremer, R. Gutbrod, S. Andersson, J. Phys. Chem. A 101, 9421 (1997).

[47] D. Zhang, W. Lei, R. Zhang, Chem. Phys. Lett. 358, 171 (2002).

[48] K.T. Kuwata, L.C. Valin, Chem. Phys. Lett. 451 186 (2008).

[49] Y. Li, H.L. Liu, X.R. Huang, Z. Li, Y.B. Sun C.C. Sun, J. Mol. Struct.: THEOCHEM. 945, 120 (2010).

[50] B.J. Finnlayson-Pitts, J.N. Pitts Jr., Chemistry of the Upper and Lower Atmosphere, Academic Press, San Diego 1999.

[51] İ. Akkurt, R.B. Ermiş, P. Baş, K. Günoğlu, Acta Phys. Pol. A 128, B-34 (2015).

[52] İ. Akkurt, S. Emikönel, F. Akarslan, K. Günoğlu, S. Kilinçarslan, İ.S. Üncü, Acta Phys. Pol. A 128, B-53 (2015).
[53] M.H. Almatarneh, A.A. Abu-Saleh, K.M. Uddin, R.A. Poirier, P.L. Warburton, Int. J. Quantum Chem. 117, 180 (2016).

[54] A.I. Alrawashdeh, M.H. Almatarneh, R.A. Poirier, Can. J. Chem. 91, 518 (2013).

[55] M.H. Almatarneh, C.G. Flinn, R.A. Poirier, W.A. Sokalski, J. Phys. Chem. A 110, 8227 (2006).

[56] K.M. Uddin, M.H. Almatarneh, D.M. Shaw, R.A. Poirier, J. Phys. Chem. A 115, 2065 (2011).

[57] M.H. Almatarneh, Ph.D. Thesis, Memorial University, St. John's, NL.

[58] M.H. Almatarneh, C.G. Flinn, R.A. Poirier, J. Chem. Inf. Model. 48, 831 (2008).

[59] M.H. Almatarneh, L. Barhoumi, B. Al-Tayyem, A.A. Abu-Saleh, M.M. Al-A'qarbeh, F. Abuorabi, Computat. Theoret. Chem. 1075, 9 (2016).

[60] M. Altarawneh, M.H. Almatarneh, A. Marashdeh, Combust. Flame 163, 532 (2016).

[61] M.H. Almatarneh, M. Altarawneh, R.A. Poirier, A. Saraireh, J. Comput. Sci. 5, 568 (2014).

[62] N.K. Kinaytürk, H. Oturak, Acta Phys. Pol. A 130, 276 (2016).

[63] H. Oturak, N.K. Kinaytürk, G. Şahın, Acta Phys. Pol. A 128, B-417 (2015).

[64] M.A. Halim, M.H. Almatarneh, R.A. Poirier, J. Phys. Chem. B 118, 2316 (2014).

[65] M. Altarawneh, A.H. Al-Muhtaseb, M.H. Almatarneh, N.W. Assaf, K.K. Altarawneh, J. Phys. Chem. A 115, 14092 (2011). 